\title{
The usefulness and ease of use of a mobile simulation application for learning of ERP systems
}

\author{
Brenda M. Scholtz ${ }^{a}$, Mando Kapeso ${ }^{a}$, M.R. (Ruth) de Villiers ${ }^{b}$ \\ ${ }^{a}$ Department of Computing Sciences, Nelson Mandela University \\ ${ }^{b}$ School of Computing, University of South Africa
}

\begin{abstract}
The hands-on use of complex, industrial Enterprise Resource Planning (ERP) systems in educational contexts can be costly and complex. Tools that simulate the hands-on use of an ERP system have been proposed as alternatives. Research into the perceived usefulness (PU) and perceived ease of use (PEOU) of these simulation tools in an m-learning environment is limited. As part of this study, an m-learning simulation application (SYSPRO Latte) was designed based on experiential learning theory and on a previously proposed theoretical framework for m-learning. The application simulates the hands-on experience of an ERP system. The purpose of this paper is to analyse the results of a study of 49 students who used SYSPRO Latte and completed a questionnaire on its PEOU and PU. The results revealed that students perceived SYSPRO Latte to be easy to use and useful, and verified other studies identifying a correlation between PEOU and PU. The study also confirmed the benefits of simulation-based learning and m-learning particularly for content presentation. The importance of considering design principles for m-learning applications was highlighted. This study is part of a larger, comprehensive research project that aims at improving learning of ERP systems in higher education.
\end{abstract}

Keywords: ease of use, enterprise systems, ERP training, m-Learning, simulation-based learning, usefulness

Categories: • Information systems $\sim$ Enterprise resource planning $\bullet$ Social and professional topics $\sim$ Information systems education $\bullet$ Applied computing $\sim$ Interactive learning environments $\bullet$ Human-centred computing $\sim$ Usability testing $\bullet$ Human-centred computing Mobile computing

\section{Email:}

Brenda M. Scholtz brenda.scholtz@mandela.ac.za (CORRESPONDING), Mando Kapeso mando.kapeso@mandela.ac.za, mulabita@live.co.za, M.R. (Ruth) de Villiers dvillmr1@unisa.ac.za, ruth.devilliers1@gmail.com

\section{Article history:}

Received: 01 Mar 2017

Accepted: 25 Jul 2017

Available online: 13 Oct 2017

\section{INTRODUCTION}

An Enterprise Resource Planning (ERP) system is a software package that integrates the business processes of an organisation as well as all information relevant for its management (Wetherbe, Turban, Leidner, \& McLean, 2007). Integration is a benefit of adopting an ERP system, resulting in other benefits such as streamlined information flow, value chain optimisation, reduced inventory

Scholtz, B.M., Kapeso, M., and de Villiers, M.R. (2017). The usefulness and ease of use of a mobile simulation application for learning of ERP systems. South African Computer Journal 29(2), 87-105. https://doi.org/10.18489/sacj.v29i2. 475

Copyright (C) the author(s); published under a Creative Commons NonCommercial 4.0 License (CC BY-NC 4.0). $S A C J$ is a publication of the South African Institute of Computer Scientists and Information Technologists. ISSN 1015-7999 (print) ISSN 2313-7835 (online). 
costs, process improvements and improved customer service. The widespread adoption of ERP systems in a broad range of industries has expanded to include not only large enterprises but also small to medium ones (Grubisic, 2014). The Gartner Forecast Analysis Report (Eid \& Granetto, 2014) predicts that the worldwide ERP software market will grow to $\$ 35.2 \mathrm{~B}$ in 2018. The leading ERP vendor is SAP AG and other large ERP vendors are Microsoft, Epicor, Sage and SYSPRO (Panorama Consulting Solutions, 2016).

The benefits that can be achieved with an ERP system are not always realised and the total cost of failure of ERP implementation is high and is fast increasing rapidly (Momoh, Roy, \& Shehab, 2010). The Panorama Consulting Solutions 2016 report (Panorama Consulting Solutions, 2016) revealed that $81 \%$ of organizations are either in the process of implementing ERP software or have completed implementation. However, the majority of organizations do not have the internal expertise necessary for achieving ERP success. Training is one approach to mitigating the risk of failed ERP projects. Other studies (Galy \& Sauceda, 2014; Dezdar, 2012; Bologa \& Lupu, 2014; Dalveren, 2014) identified that poor quality training and education are key factors contributing to ERP system project failure. A case study conducted in Pakistan (Shah, Bokhari, Hassan, Shah, \& Shah, 2011) confirms how training significantly influences the success of ERP system adoption within an organisation. As employees improve their skills with using an ERP system, tasks can be achieved more efficiently, thereby improving an organisation's performance (Bologa \& Lupu, 2014).

The results of studies in Africa revealed a lack of skills in business process management and ERP projects (Abdullabhai \& Acosta, 2012; Ansen, 2014; Otieno, 2010; Scholtz, Cilliers, \& Calitz, 2011; Wamicha \& Seymour, 1999; Garbutt \& Seymour, 2015). This demand for skills has prompted Higher Education Institutions (HEIs), as well as business organisations, to conduct research into establishing models and best practices for achieving efficient and effective learning of ERP system concepts and skills (Dalveren, 2014; Oberer \& Erkollar, 2013; Little, 2012). As a result ERP courses have been introduced into the curricula of HEIs globally in developed countries (Khoury, Rich, \& Jenab, 2015) as well as in developing countries (Dalveren, 2014; Mahanga \& Seymour, 2015).

Research at the University of Houston (Bressler, 2014) revealed that a learning mechanism that involves active learning and hands-on activities enhances the understanding of ERP systems and the role they can play in an organisation. Both students in HEIs and learners in industry who have had little or no exposure to ERP systems are termed novice ERP users and need to learn introductory ERP concepts, modules and processes (Whale, 2015). In both industry and education, approaches to learning can vary from traditional face-to-face learning approaches to distance learning environments such as electronic learning (e-learning) and mobile learning (m-learning).

e-Learning has been described as the use of the internet for interaction with learning content, instructors and peers (Ettinger, Holton, \& Blass, 2006). m-Learning is a subset of e-learning and refers to learning conducted on mobile devices from multiple locations, across multiple time zones and where the content is readily accessible (Oberer \& Erkollar, 2013). A combination of these approaches is used in both industry training environments and in HEIs. The benefits of simulations and visualisations for learning have been reported, particularly in HEIs (Motiwalla, 2007; Plass, Homer, \& Hayward, 2009) and have been cited as critical success factors of both m-learning and e-learning (Scholtz \& Kapeso, 2014). Simulation-based learning offers a practical and experiential 
learning experience in a controlled environment, which can be reflected on and practiced in one's own time (Fanning \& Gaba, 2007). ERPsim is one such application (app), which simulates the SAP ERP system designed to teach fundamental and advanced ERP system concepts and to demonstrate how to use ERP systems (Léger \& Michon, 2011). However, it is very complex for novices to set up and use, and is costly. The primary benefits of using simulators for learning software, compared with actual hands-on use, are reduction in the need for resource intensive software and decreased internet access.

Mobile device adoption has grown exponentially in both developed and developing countries (EMarketer, 2014). The estimated number of users worldwide in 2014 was 1.75 billion (Barker, Krull, \& Mallinson, 2005). In Africa there are more mobile phones than adults (Mutiga \& Flood, 2016). In the wealthier countries in the developing world, such as South Africa, mobile devices are owned by $89 \%$ of people. On the other hand countries in poorer regions such as Uganda and Kenya have lower adoption levels (65\% and $83 \%$ and 65\% respectively). Whilst many users have feature phones with limited internet and simple apps, smart phone adoption in Sub-Saharan Africa is forecast to grow the most and it is predicted that over half of the connection base will have smart phones by 2020 (GSMA Intelligence, 2014). The growth of mobile technology in many third world countries in Africa has driven the adoption of m-learning (Manji, Jal, Badisang, \& Opoku-Mensah, 2015). The assumption of m-learning is that learners are always on the move and therefore, in order for learning to work, it needs to be reconceptualised. Several studies (Oberer \& Erkollar, 2013; Scholtz \& Kapeso, 2014; Bajpai, 2011) been done to identify m-learning models and the critical success factors of m-learning. Factors identified are mobility/portability, content presentation, continuous access to content and the ability to download and view content offline (Alrasheedi \& Capretz, 2014; Nedungadi \& Raman, 2012; Sharma \& Kitchens, 2004).

The purpose of this paper is to investigate and report on the impact of the application of the Experiential Learning Theory (ELT) to ERP education in HEIs. In order to do this a newly designed m-learning app called SYSPRO Latte was developed, based on pertinent literature as a proof of concept, and evaluated by the students in terms of its acceptance and usefulness. Both qualitative and quantitative data collection methods were used to evaluate the usefulness of the app. This study builds on previous work (Scholtz \& Kapeso, 2014) and this paper focuses on students' perceptions of using the app to learn ERP concepts, and the usefulness of the simulator aspect of the app to simulate actual tasks performed in SYSPRO.

The structure of the paper is as follows: Section 2 provides a background to the field of experiential learning and m-learning. In Sections 3 and 4 a literature review of m-learning in the context of ERP systems and technology acceptance theory is presented. The next two sections discuss the design of SYSPRO Latte and the research design of the study. The results of the evaluation of the m-learning app are then analysed and reported in the next section. Finally, the conclusion presents reflections and possibilities for future research. 


\section{PEDAGOGICAL THEORIES AND M-LEARNING}

Experiential Learning Theory (ELT) has steadily gained acceptance since its proposal in 1971 (Kolb, MacIntyre, \& Rubin, 1971) and is now recognised as a useful tool for improving teaching and learning in higher education. Education has changed significantly from the traditional teachercentred, knowledge-transfer approach to one that is focused on the learner as an active participant (learner-centred). Frontczak (1998) proposed a shift to experiential, interactive methods of learning that are rich in both scope and variety and limited only by the imagination of the educator. Several studies (Fenwick, 2001; Jewer \& Evermann, 2014; Kirkham \& Seymour, 2005) have proposed the use of ELT for achieving competency of students in IT-based courses by adopting a hands-on approach to using and learning software. In order to promote a positive attitude towards learning or training of adults, the learning should be problem-centred and significant to real life situations. ELT and simulation-based learning are ideal for professionals in the working environment. They target adult audiences, which may pose challenges when used for student learning (Fanning \& Gaba, 2007). Simulation-based learning is the application of learning in a real or simulated environment (Shih, 2007; Uzunboylu, Cavus, \& Ercag, 2009). A simulation can be defined as "something that is made to look, feel or behave like something else especially so that it can be studied or used to train people" and/or "the imitative representation of the functioning of one system or process by means of the functioning of another" (Merriam-Webster, n.d.). An ERP simulation game was proposed and designed for improving competencies such as ERP transaction skills, ERP management knowledge and business process knowledge (Cronan, Léger, Robert, Babin, \& Charland, 2012). The study results revealed that the simulation game supported a unique and alternative method for improving learning and training of users in the effective use of ERP. Their study also showed that research is required regarding what aspects of simulation-based learning of ERP systems are more effective.

Technological advances have reduced possible prohibiting variables by providing location- and time-independence. However, e-learning is not always ideal in the work environment. Users who make considerable use of their computers for work purposes may not be inclined to use them as learning tools. In addition, desktop computers cannot be used on the move since they are not mobile (Ettinger et al., 2006). m-Learning has been described as "learning conducted in multiple locations, across multiple time zones and the content is accessible through various devices" (Oberer \& Erkollar, 2013; Korucu \& Alkan, 2011) including smart phones, tablets, PDAs, MP3 players, portable game devices and iPads (Jacob \& Issac, 2014). The emergence of these devices has facilitated the growth of m-learning, thus playing a key role in fulfilling the primary goals of distance education for geographically-dispersed persons and groups (Uzunboylu et al., 2009). These devices provide opportunities for interactivity through a combination of features such as audio, video, text document editing and storage of data (Korucu \& Alkan, 2011).

Some authors define m-learning as a service or tool that helps learners acquire knowledge through the provision of electronic information and educational content independently of time and location (Oberer \& Erkollar, 2013). By its nature, m-learning is a type of distance learning and e-learning; however, it has several advantages over e-learning, namely:

- It is independent of location and time (Bajpai, 2011); 
- Most mobile devices have a lower cost of acquisition compared to most desktop PCs, including the overhead costs of maintenance (Manji et al., 2015);

- Mobile devices are generally smaller and lighter, hence are better suited for portability (Ettinger et al., 2006; Uzunboylu et al., 2009); and

- The use of GPS and GSM technologies enable m-learning to more readily provide locationdependent educational content (Bajpai, 2011).

\section{M-LEARNING FOR ERP SYSTEMS}

A framework for ERP m-learning that takes into account the factors for success in e-learning, as well as the additional factors required for m-learning has been proposed (Figure 1) (Scholtz \& Kapeso, 2014). The framework caters for three main stakeholders of ERP learning, namely the ERP consultant, the ERP student and the ERP user. The first component of the framework is the content presentation component, which includes the main elements required of e-learning and m-learning applications to support teaching and learning of ERP systems, such as textual content, video, demonstrations and simulations. The framework incorporates a Learning Management System (LMS), which is an information system with a well-defined educational purpose that is focused on the processes of collaboration and communication (Zhang \& Wang, 2005). The central component of the framework comprises four elements, namely: the LMS, as described above; the actual ERP system (for example, SAP); a database of ERP concepts and processes; and the learner profile. The learner profile is essential for a constructivist or learner-based approach which positions the learner at the centre of the educational process and making learners responsible for acquiring their skills (Nordin, Embi, \& Yunus, 2010; Conková, 2013).

Factors proposed (Scholtz \& Kapeso, 2014) to influence the success of m-learning of ERP systems are:

- Coordination

- Mobility

- Communication

- Content (easily accessible and available offline)

- Adaptive to different devices and learner's level of knowledge, and

- Application of learning in real or simulated environments.

An advantage of e-learning and thus of m-learning is the facility it provides for users to download and view material and content offline (Dalveren, 2014). When designing m-learning apps, the context of use of the users and the learning content presented need to be suitable for mobile devices (Nedungadi \& Raman, 2012). Screen sizes and the type of device should be considered during the design and 
development of the m-learning application, which could be a challenge due to the smaller screen sizes (Nedungadi \& Raman, 2012). The content to be presented should be resource conscious (Nordin et al., 2010). The portability, social interactivity and connectivity of mobile devices provide new capabilities for learning and ease of integration into the classroom (Minović, Štavljanin, Milovanović, \& Starčević, 2008). Communication between learners and between learners and teacher are key aspects to be provided by m-learning (Udanor \& Nwodoh, 2010).

Infrastructure is also a highly important factor for both e-learning and m-learning, since extensive wi-fi coverage and bandwidth can be required to accommodate the large number of mobile devices used by students, faculty and staff (Krotov, 2015). Using a mobile device to download and upload multimedia content puts additional strain on wi-fi bandwidth. Classrooms also need proper power outlets so that students can recharge these devices.

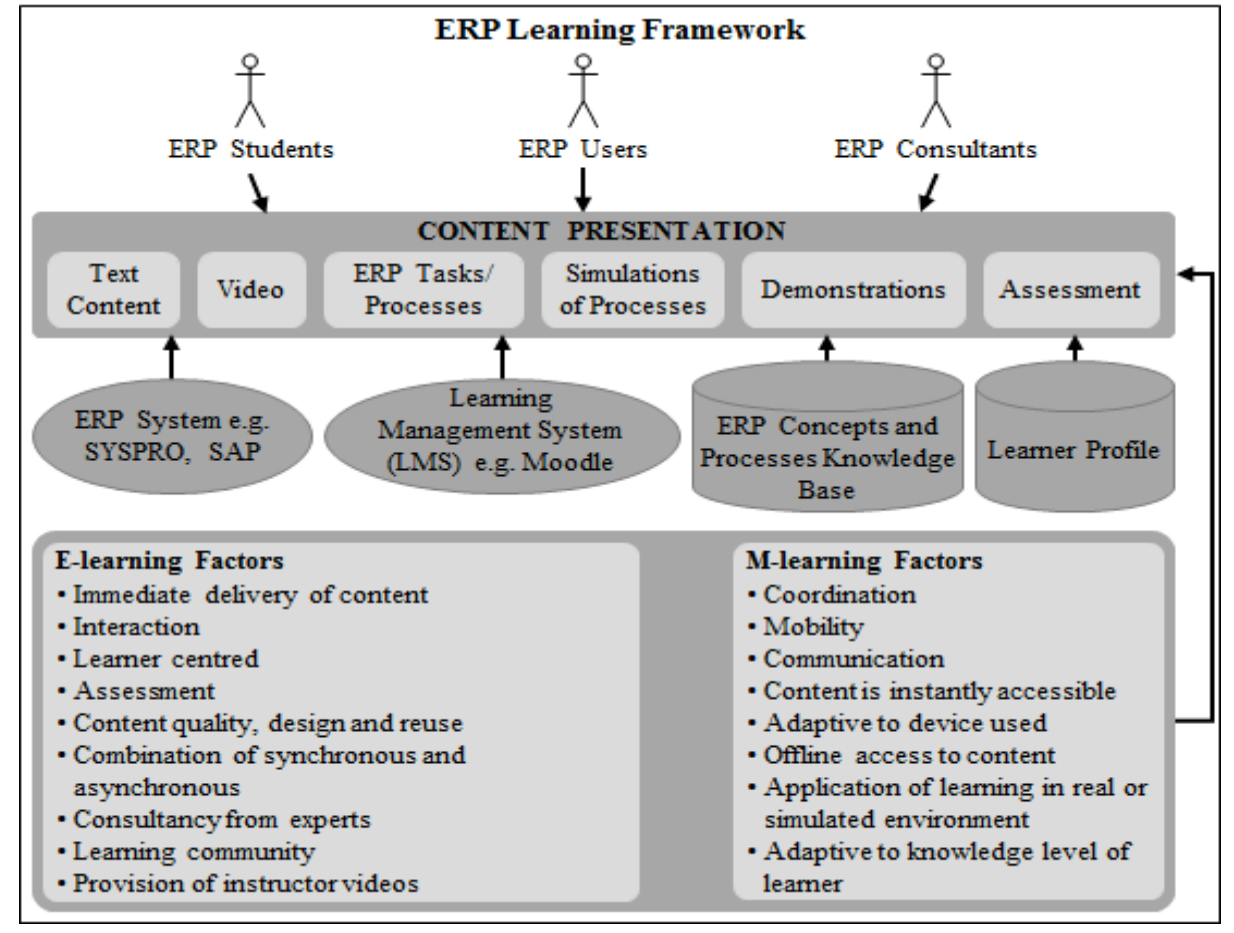

Figure 1: Framework for e-learning of ERP systems (Scholtz \& Kapeso, 2014)

\section{TECHNOLOGY ACCEPTANCE THEORY}

Various researchers have adopted the Technology Acceptance Model (TAM) in an effort to understand the reasons that individuals choose to adopt or not to adopt specific technologies for performing a task (Escobar-Rodríguez \& Bartual-Sopena, 2015; Wallace \& Sheetz, 2014; Amoako-Gyampah \& Salam, 2004). In studies of ERP systems, TAM has also been used to investigate the effect of external factors 
on the behaviour and attitude of end users (Amoako-Gyampah \& Salam, 2004). The foundation of TAM is the theory of reasoned action, which argues that an individual's behavioural intention influences his/her performance for carrying out a specified task (Davis, Bagozzi, \& Warshaw, 1989). The two variables that TAM is based on are those that influence the adoption of a system, and are Perceived Usefulness (PU) and Perceived Ease of Use (PEOU). It has been shown that attitudes towards using a system are influenced by both the PU and the PEOU of that system (Davis et al., 1989). Therefore, a high PU and a high PEOU result in a high positive attitude towards use of the system by the end user. PU can be described as the extent to which an individual believes using a particular system will improve his/her work performance. PEOU refers to the extent to which an individual believes that using a particular system would be effortless. Some studies reported a positive correlation between PU and PEOU (Agrifoglio \& Metallo, 2009; Kerimoglu, Basoglu, \& Daim, 2008); whilst others (Agrifoglio \& Metallo, 2009; Ali, Younes, et al., 2013; Al-Jabri \& Roztocki, 2015) ignored this relationship. In the present study, however, this relationship is explored further.

\section{DESIGN OF THE MOBILE SIMULATION APPLICATION (SYSPRO LATTE)}

SYSPRO is known for being one of the longest standing and largest independent, international ERP business solution vendors (SYSPRO, n.d.). At the time of writing this paper, existing SYSPRO e-learning systems allow users to watch video tutorials of demonstrations, training and assessments of specific tasks performed in the actual ERP system. However, these are not interactive simulations and are designed only for desktops, thus motivating the need for the proposed SYSPRO Latte application and for it to be implemented via m-learning. Many students in Africa have access to smart phones, but no access to laptops or desktop computers off-campus (Oyedemi, 2012). Simulations have several benefits over hands-on training with the actual software system, since users do not need access to the ERP system itself, which can be resource intensive.

Therefore, as part of this work, SYSPRO Latte was developed as a mobile app that can be used to assist with the training and education of SYSPRO users. The design of the app was guided by theory related to ELT and the framework for e-learning of ERP systems (Figure 2).

The primary objective of the SYSPRO m-learning app was to support the teaching and learning of ERP systems by providing learning material for use anywhere and anytime. The SYSPRO Latte app has three main features: viewing of content (text-based and video), hands-on simulation, and assessment. The textual and video content provided by the app consists of a dynamic animated illustrative collection of the structure of the tasks and activities that make up a business process within ERP. The assessment features allow integration with the Moodle e-learning system. The hands-on simulation of SYSPRO Latte (Kapeso, 2014) provides a replicated simulated environment of the SYSPRO ERP system, specifically of tasks in the procurement processes.

SYSPRO Latte was developed on an Android platform and the simulation feature was implemented by using a series of static screenshots that represent different windows within the SYSPRO ERP application. A chronological sequence of windows is captured for display to a user as he/she completes a task within the SYSPRO system. By means of the hands-on simulation on a mobile device, users are presented with a similar look and feel to that of working in the live SYSPRO system. 


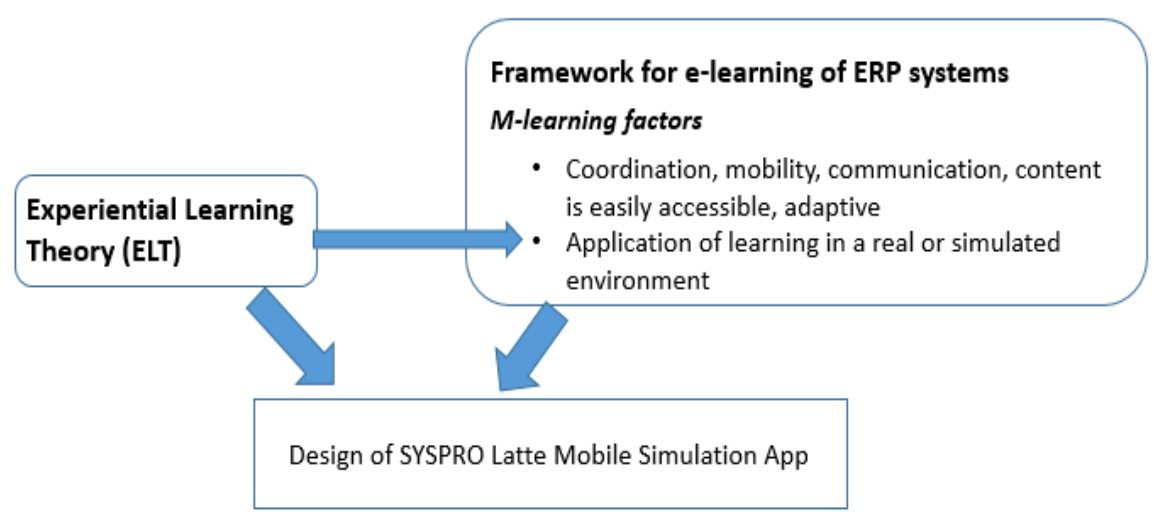

Figure 2: Theory driven design of mobile simulation app

The Snipping Tool captured screenshots of windows within the SYSPRO system when an event is triggered, for instance, clicking a folder icon to expand a window. Users can choose to work either in novice- or expert mode. The novice mode includes hints in red blocks that advise and assist the user in completing the task, whereas the expert mode provides no tips (Figure 3). The steps required to complete the task are shown in the left pane and a green tick indicates that the specific step has been completed. Once the task has been successfully completed, a message appears on the screen.

\section{RESEARCH DESIGN}

\subsection{Research model}

The TAM model has been used to predict the adoption of a new technology by users through their perception of usefulness and ease of use (Ngai, Poon, \& Chan, 2007) and has been used in several other e-learning studies (Wallace \& Sheetz, 2014; Ngai et al., 2007; Albert \& Tullis, 2013). In this study, the ELT and the framework for e-learning of ERP systems (Figure 1) were used to motivate the design and development of the SYSPRO Latte simulation app. Evaluation of the app was guided by the TAM theory. Participants used the app and then evaluated its ease of use and usefulness to determine its PU and PEOU and to provide general user perceptions of the app. The relationship between PU and PEOU was also investigated in order to aid the understanding of m-learning systems and their usability. The premise is that if it is easy to use, it will be deemed useful. In addition to the quantitative data obtained from the TAM model, qualitative data was acquired to gain a richer understanding of the usability issues around interacting with simulation-based learning apps on a mobile platform.

The hypotheses in this study are (Figure 4):

Ho. M-learning and simulation are not regarded as useful by students. 


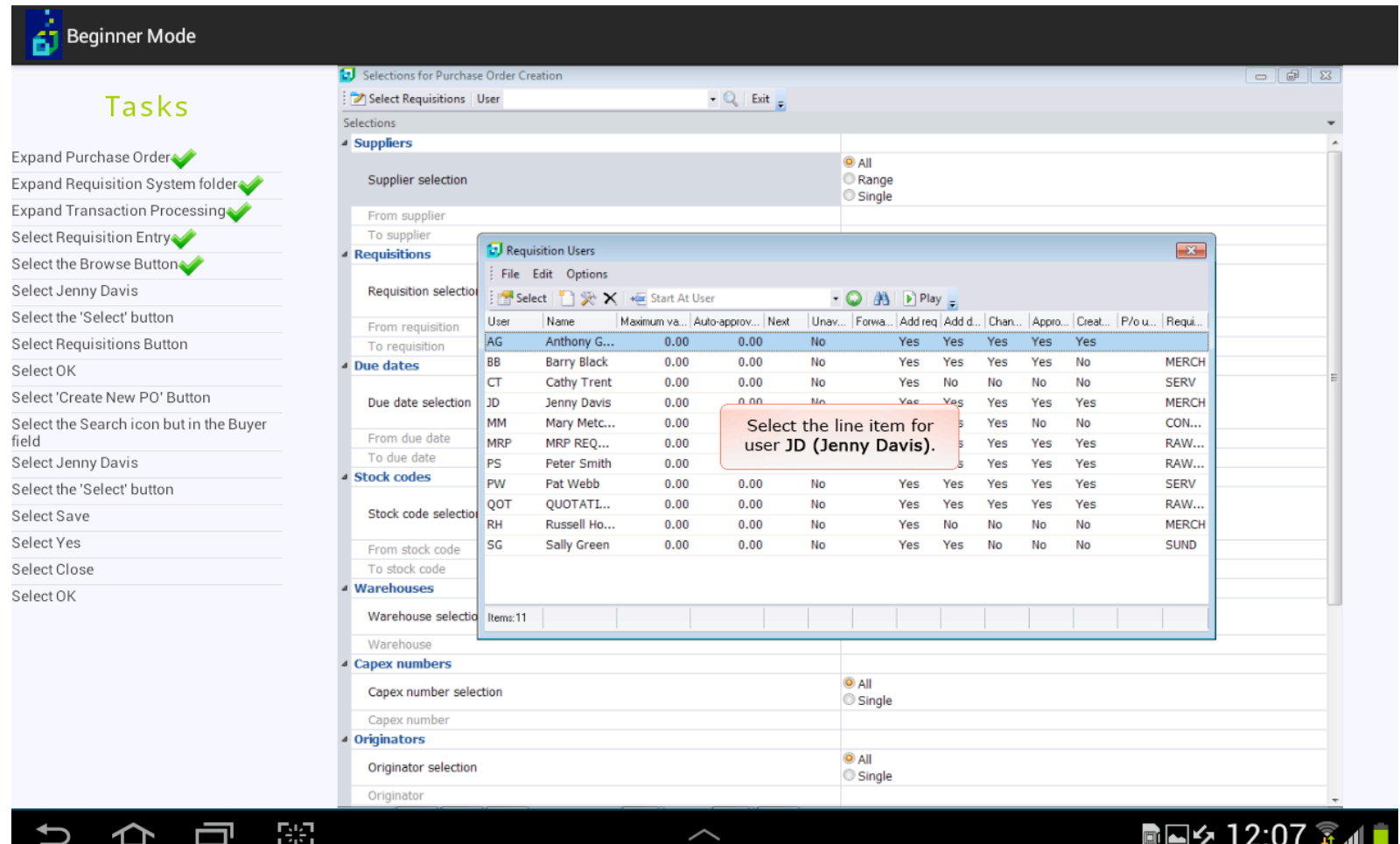

Figure 3: Screenshot of SYSPRO Latte Simulation (Novice Mode)

H1. The m-learning app has a high PEOU.

H2. The m-learning app has a high PU.

H3. A correlation can be established between PEOU and PU.

\subsection{Tasks and participants}

Participants in the study were students at a South African HEI enrolled for a business systems undergraduate module in the Computing Sciences department, fitting the profile of typical novice ERP learners. This module contains learning outcomes related to the understanding of introductory ERP knowledge and skills. All participants signed an online consent form, and were assured that data would be confidential and that their responses to the survey would in no way influence their module grades. Convenience sampling was used to select participants; this is a non-probability sampling technique whereby participants are selected based on their convenient accessibility and proximity to the researcher (Albert \& Tullis, 2013). Participants were required to perform several tasks representing all the features of the application, with the main focus on the hands-on simulation (Appendix A). The participants were provided with mobile devices for them to perform the tasks. 


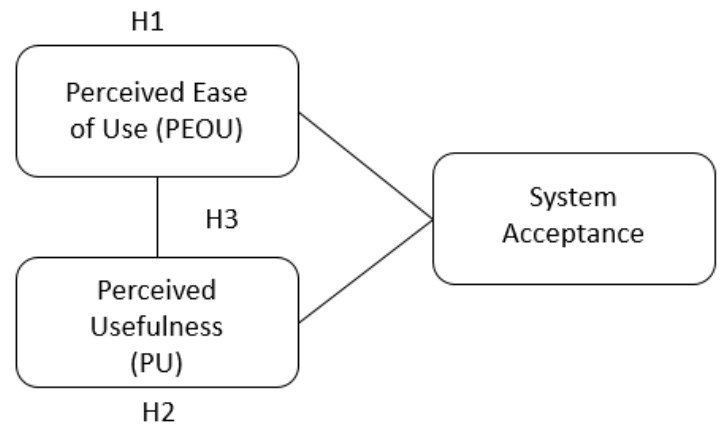

Figure 4: Research hypotheses

Tasks were provided by instructions on a task list. The evaluation was conducted in a controlled environment in a computer lab.

\subsection{Research instrument}

The research instrument was a post-task questionnaire related to the adoption of technology based on the TAM proposed by Davis et al. (1989). The first section in the questionnaire comprised Likert Scale items where participants had to provide ratings for PEOU and PU. The second part was an extension of the TAM, where open-ended questions were asked to determine a more in-depth understanding of the positive and negative features of the app. Three common items are used as metrics for PEOU and were included in the questionnaire, namely:

- I found the system easy to use,

- Learning to use the system was easy for me, and

- It was easy to become skilful at the system,

The five items used to describe PU that were included are:

- The system will be of use and benefit to me;

- The system can improve my performance (with ERP);

- The system can help me accomplish my tasks more efficiently;

- The system is useful for my ERP studies; and

- The system can help me be more productive.

Furthermore, a pilot study was conducted where participants were lecturers who are experts in User Interface design, but are novice ERP users. A second pilot study was conducted by a SYSPRO expert. 


\begin{tabular}{|l|c|c|}
\hline & Mean & S.D. \\
\hline I found the SYSPRO m-learning app easy to use & 4.51 & 0.58 \\
Learning to use the SYSPRO m-learning app was easy for me & 4.51 & 0.68 \\
It was easy to become skilful at using the SYSPRO m-learning system & 4.20 & 0.71 \\
\hline
\end{tabular}

Table 1: Frequency Distributions for PEOU $(n=49)$

\subsection{Reliability}

The reliability of the questionnaire was examined using Cronbach's coefficient alpha values for PEOU and PU. As presented in Appendix B, all alpha values were above or close to 0.8, which is regarded as excellent (Santos, 1999).

\section{RESULTS AND DISCUSSION}

\subsection{Participant profile}

A total of 49 undergraduate students took part in the study of whom ten were female (20\%) and 39 were male $(80 \%)$. Their age distribution ranged from 18 to $25(n=45)$ and 26 to $40(n=4)$. The most commonly owned mobile device was the tablet (51\%), with mobile phones being the second-most common (18\%). Fourteen percent (14\%) of participants did not have access to a mobile device.

\subsection{Sample and inferential statistics}

A 5-point Likert scale was used for rating the eight TAM metrics, where 1 is Strongly Disagree and 5 is Strongly Agree. The population mean values for $\mathrm{HO}$ were selected according to the applicable threshold values for the 5-point Likert response scale that was used in the study, i.e. very negative 1.00-1.79; negative 1.80-2.59; neutral 2.60-3.40; positive 3.40-4.19; very positive 4.20-5.00. For testing the hypotheses, a mean rating was regarded as 'high' if it was either positive or very positive.

All the PEOU metrics had overall mean ratings in the very positive range (Table 1 ). The two metrics which equally had the highest rated overall mean $(\mu=4.51)$ were "I found the SYSPRO m-learning app easy to use" and "Learning to use the SYSPRO m-learning app was easy for me". All the PU metrics had overall mean ratings in the positive range (Table 2). The highest rated metric was "Using the SYSPRO m-learning system can improve my performance with ERP Systems" $(\mu=4.27)$. The metric with the lowest overall mean for PU was "Using the SYSPRO m-learning system can assist me with doing my ERP tasks more efficiently/productively" $(\mu=4.06)$, but this was still a positive rating.

Table 3 presents the results of one-sample t-tests for the PEOU and PU, the null-hypotheses, standard deviation and inferential statistics of each variable. The observed sample mean of PEOU was in the very positive range $(\mu=4.41)$ and for PU was in the positive range $(\mu=4.15)$. The null-hypothesis value for PEOU and PU was derived based on the lower range value in the mean range 


\begin{tabular}{|l|c|c|}
\hline & Mean & S.D. \\
\hline I think the SYSPRO m-learning system will be of use and benefit to me & 4.08 & 0.81 \\
Using the SYSPRO m-learning system can improve my performance with & 4.27 & 0.67 \\
ERP systems & & \\
Using the SYSPRO m-learning system can enable me to accomplish ERP & 4.16 & 0.77 \\
tasks more efficiently & & \\
I found the SYSPRO m-learning system useful for my ERP studies & 4.16 & 0.87 \\
Using the SYSPRO m-learning system can assist me with doing my ERP & 4.06 & 0.75 \\
tasks more efficiently/productively & & \\
\hline
\end{tabular}

Table 2: Frequency distributions for PU $(n=49)$

\begin{tabular}{|l|c|c|c|c|c|c|}
\hline & Null hypothesis & \multicolumn{2}{|c|}{ Sample statistics } & \multicolumn{3}{|c|}{ Inferential Statistics } \\
\hline & & Mean & S.D. & t & P (d.f. $=48)$ & Cohen's d \\
\hline Perceived Ease Of Use (PEOU) & $\mu=4.2$ & 4.41 & 0.57 & 2.57 & .013 & 0.37 \\
Perceived Usefulness (PU) & $\mu=3.4$ & 4.15 & 0.63 & 3.84 & $<.0005$ & 0.55 \\
\hline
\end{tabular}

Table 3: Inferential statistics for the factors $(n=49)$

for very positive and positive ranges respectively. The hypothesised mean of the null-hypothesis for the PEOU was thus the lower range value of very positive $(\mu=4.2)$ and for PU was positive $(\mu=3.4)$. Since the observed sample mean was $\mu=4.41$, it can be deduced that the users found SYSPRO Latte very easy to use. Since hypothesis H1 for PEOU is significant, this implies that $\mathrm{H} 1$ can be supported and the result can be generalised to the sampled population. Hypothesis $\mathrm{H} 2$ for PU is also supported as the mean $\mu=4.15$ is in the positive range and greater than the null-hypothesis mean $(\mu=3.4)$. A positive rating is regarded as high; therefore it can be concluded that SYSPRO Latte is perceived as useful by the sample population. The Cohen's d values revealed a small significance for PEOU and a moderate practical significant difference for PU. Correlations are statistically significant at 0.05 level for $n=49$ if $|r|>=.282$ and practically significant if $|r|>=.300$. Thus significant (both statistically and practically) if $|r|>=.300$ (Gravetter \& Wallnau, 2009).

A Pearson Product Moment Correlations test was performed in order to determine the correlation between PEOU and PU. The correlation between PEOU and PU was found to be significant both statistically and practically with a correlation value of 0.380 . This correlation can be described as moderately strong and therefore hypothesis $\mathrm{H} 3$ is supported. From this it can be deduced that those participants who had a high PEOU score also tended to have a high PU score, which confirms previous research (Agrifoglio \& Metallo, 2009; Kerimoglu et al., 2008).

\subsection{Qualitative analysis}

Open-ended questions were used to obtain qualitative feedback on participants' perceived best and worst features of the app. The qualitative data was thematically analysed by using categories and themes (Braun \& Clarke, 2006). Thematic analysis involves the identification, analysis and reporting of patterns called themes within data that is collected and organised and that describes large sets of qualitative data. This is done to interpret several aspects of a particular research topic. The various 


\begin{tabular}{|l|c|l|}
\hline Theme & Frequency $(f)$ & Sample comment \\
\hline Simulation & 13 & Getting the actual feel of the SYSPRO system \\
Ease of use & 11 & It is easy to use \\
Content presentation & 11 & The content is very straight forward and useful \\
\hline
\end{tabular}

Table 4: Top Three Positive Themes

\begin{tabular}{|l|c|l|}
\hline Theme & Frequency $(f)$ & Sample comment \\
\hline $\begin{array}{l}\text { Icon sizes on simulation } \\
\text { Content presentation }\end{array}$ & 13 & $\begin{array}{l}\text { The font and the buttons were too small and difficult to see } \\
\text { Sub-heading and bullet points in course notes within the app } \\
\text { not clearly identifiable } \\
\text { Text size }\end{array}$ \\
\hline
\end{tabular}

Table 5: Top Three Negative Themes

themes identified were assigned to the responses in order to obtain a frequency count for each theme and then categorised into positive and negative features. The top three positive themes identified (Table 4) were simulation $(f=13)$, ease of use $(f=11)$, and content presentation $(f=11)$. One participant stated that "The novice mode tutorial was very easy to follow and very clear to understand". Another highlighted the ease of accessibility of menu items and navigation through the app as a positive feature. This confirms the positive quantitative ratings of the SYSPRO Latte simulation application and also verifies other studies (Motiwalla, 2007; Fanning \& Gaba, 2007; Plass et al., 2009) citing the benefits of simulation-based learning.

Analysis of the open-ended comments revealed that the most frequently reported negative feature of SYSPRO Latte was the size of the icons in the simulation $(f=14)$. This was followed by the size of the text $(f=7)$ and the presentation of the content $(f=6)$. Other concerns related to the quality of content presentation; for example, the module information presented in the SYSPRO Latte app was too textual or the information layout was inconsistent. For instance, one participant highlighted the need for better paragraph spacing and structure of the main points within the paragraphs. Table 5 summarises the top three negative features of the SYSPRO Latte that were identified.

\section{CONCLUSIONS AND RECOMMENDATIONS}

ERP systems are used to integrate and manage the information and business processes of organisations, necessitating the inclusion of ERP modules into the curricula of computing-related departments at HEIs. One way of teaching and learning ERP is via hands-on training that simulates use of an ERP system. This paper describes SYSPRO Latte, an m-learning simulation app, which was designed on underlying theoretical foundations. In particular, the development of SYSPRO Latte was guided by experiential learning theory (ELT) (Kolb et al., 1971), as it simulated the hands-on use of an ERP system and exposed students to an experience akin to that of using an authentic ERP system. In addition, SYSPRO Latte is a practical implementation of a conceptual framework for m-learning of ERP systems (Scholtz \& Kapeso, 2014). The framework incorporates a set of factors that promote success in m-learning of ERP systems. Use of the simulated software allows students to learn the 
system and to get to know the look and feel of the software without requiring them to have expensive hardware, resource-intensive software or internet access. In a developing country like South Africa, this can be a great advantage.

Similarly, the evaluation of SYSPRO Latte was grounded in a theoretical model, namely TAM (Davis et al., 1989). The empirical results indicate that both the PU and PEOU for using the mobile simulation app to support ERP learning, were high. In other words, the m-learning app was regarded as useful and easy to use. The study also revealed that a correlation can be established between PEOU and PU, and therefore if a user regards software as easy to use, they would usually also regard it as useful. Whilst the sample size was relatively small, it was still large enough to allow generalisation to the sample population. This work contributes to pedagogic knowledge in HEI's by providing a demonstration of the value of simulation-based experiential learning, which can be applied in other educational environments, as well as in workplace training.

The results of this study revealed that adopting m-Learning is not a guarantee of success and despite the benefits of m-learning for students on the move, the design of these systems needs to be properly considered. For example, the small screen size of mobile devices can be a limitation for simulations of complex software such as ERP systems. Future research could therefore compare the perceptions of students using a simulation app on phones and tablets with those using it on a device with a larger screen size such as a laptop or desktop. Whilst the TAM was successfully used in this study to evaluate the app, future research could also investigate other evaluation methods that provide greater insight into usability issues than TAM. Studies could be done on m-learning in other developing countries and the findings compared with those in developed countries. Finally, the impact of using SYSPRO Latte on students' performance on ERP tasks can be compared with the performance of students who learned to do ERP tasks in conventional class-based teaching.

\section{References}

Abdullabhai, M. \& Acosta, F. (2012). Impact of adopting Enterprise Resource Planning systems by commercial organizations in Kenya. DLSU Business \& Economics Review, 21(2).

Agrifoglio, R. \& Metallo, C. (2009). The role of affective commitment in ERP Adoption: An empirical study. In MCIS (p. 110).

Albert, W. \& Tullis, T. (2013). Measuring the user experience: Collecting, analyzing, and presenting usability metrics. Oxford: Morgan Kaufmann.

Ali, B. M., Younes, B. et al. (2013). The impact of information systems on user performance: An exploratory study. Journal of Knowledge Management, Economics and Information Technology, $3(2), 128-154$.

Alrasheedi, M. \& Capretz, L. F. (2014). Learner perceptions of a successful mobile learning platform: A systematic empirical study. In Proceedings of the World Congress on Engineering and Computer Science (Vol. 1).

Amoako-Gyampah, K. \& Salam, A. F. (2004). An extension of the technology acceptance model in an ERP implementation environment. Information \& management, 41(6), 731-745. https: //doi.org/10.1016/j.im.2003.08.010 
Ansen, J. B. (2014). Sustainably developing e-skills in Africa: A case with enterprise resource planning (ERP) system. Journal of Emerging Trends in Educational Research and Policy Studies, 5(8), 148.

Bajpai, M. B. R. (2011). M-learning \& mobile knowledge management: Emerging new stages of e-learning \& knowledge management. International Journal of Innovation, Management and Technology, 2(1), 65.

Barker, A., Krull, G., \& Mallinson, B. (2005). A proposed theoretical model for m-learning adoption in developing countries. In Proceedings of mLearn (Vol. 2005, 4th).

Bologa, R. \& Lupu, A. R. (2014). Organizational learning networks that can increase the productivity of IT consulting companies. A case study for ERP consultants. Expert Systems with Applications, 41(1), 126-136. https://doi.org/10.1016/j.eswa.2013.07.016

Braun, V. \& Clarke, V. (2006). Using thematic analysis in psychology. Qualitative research in psychology, 3(2), 77-101. https://doi.org/10.1191/1478088706qp063oa

Bressler, L. (2014). Teaching an online accounting information systems course: Student perceptions of SAP/ERP active learning. Journal of Finance and Accountancy, 15, 1.

Conková, M. (2013). Analysis of perceptions of conventional and e-learning education in corporate training. Journal of Competitiveness, 5(4). https://doi.org/10.7441/joc.2013.04.05

Cronan, T. P., Léger, P.-M., Robert, J., Babin, G., \& Charland, P. (2012). Comparing objective measures and perceptions of cognitive learning in an ERP simulation game: a research note. Simulation \& Gaming, 43(4), 461-480. https://doi.org/10.1177/1046878111433783

Dalveren, Y. (2014). Using e-learning in enterprise resource planning (ERP) training: A case study to assist curriculum designers in Turkey. Procedia-Social and Behavioral Sciences, 116, 1353-1357. https://doi.org/10.1016/j.sbspro.2014.01.396

Davis, F. D., Bagozzi, R. P., \& Warshaw, P. R. (1989). User acceptance of computer technology: A comparison of two theoretical models. Management science, 35(8), 982-1003. https://doi. org/10.1287/mnsc.35.8.982

Dezdar, S. (2012). Strategic and tactical factors for successful ERP projects: Insights from an Asian country. Management Research Review, 35(11), 1070-1087. https:// doi.org/10.1108/ 01409171211276945

Eid, T. \& Granetto, B. (2014). Forecast analysis: Enterprise application software, worldwide, 2Q14 update. Last checked: 30 Sep 2017. Retrieved from https://www.gartner.com/doc/2863924/ forecast-analysis-enterprise-application-software

EMarketer. (2014). Smartphone users worldwide will total 1.75 billion in 2014. Last checked: 30 Sep 2017. Retrieved from https://www.emarketer.com/Article/Smartphone-Users-WorldwideWill-Total-175-Billion-2014/1010536

Escobar-Rodríguez, T. \& Bartual-Sopena, L. (2015). Impact of cultural factors on attitude toward using ERP systems in public hospitals. Revista de Contabilidad, 18(2), 127-137. https://doi. org/10.1016/j.rcsar.2014.04.002

Ettinger, A., Holton, V., \& Blass, E. (2006). E-learner experiences: Key questions to ask when considering implementing e-learning. Industrial and commercial training, 38(3), 143-147. https: //doi.org/10.1108/00197850610659409 
Fanning, R. M. \& Gaba, D. M. (2007). The role of debriefing in simulation-based learning. Simulation in healthcare, 2(2), 115-125. https://doi.org/10.1097/SIH.0b013e3180315539

Fenwick, T. (2001). Experiential learning: A theoretical critique from five perspectives. Information Series no. 385.

Frontczak, N. T. (1998). A paradigm for the selection, use and development of experiential learning activities in marketing education. Marketing Education Review, 8(3), 25-33. https://doi.org/ 10.1080/10528008.1998.11488641

Galy, E. \& Sauceda, M. J. (2014). Post-implementation practices of ERP systems and their relationship to financial performance. Information \& Management, 51(3), 310-319. https://doi.org/10. 1016/j.im.2014.02.002

Garbutt, M. \& Seymour, L. F. (2015). Enterprise systems competencies-Supplying the skills-The novice practitioner perspective. In 9th IDIA Conference, Zanzibar (pp. 8-9).

Gravetter, F. \& Wallnau, L. (2009). Statistics for the behavioral sciences. Available Titles Aplia Series. Wadsworth. Retrieved from https://books.google.co.za/books?id=wWFmkwxSUfUC

Grubisic, I. (2014). ERP in clouds or still below. Journal of Systems and Information Technology, 16(1), 62-76. https://doi.org/10.1108/JSIT-05-2013-0016

GSMA Intelligence. (2014). The mobile economy: Sub-Saharan Africa 2014. Last checked: 03 Oct 2017. GSMA. Retrieved from https://www.gsma.com/mobileeconomy/archive/GSMA_ME_ SubSaharanAfrica_2014.pdf

Al-Jabri, I. M. \& Roztocki, N. (2015). Adoption of ERP systems: Does information transparency matter? Telematics and Informatics, 32(2), 300-310. https://doi.org/10.1016/j.tele.2014.09.005

Jacob, S. M. \& Issac, B. (2014). The mobile devices and its mobile learning usage analysis. arXiv preprint arXiv:1410.4375.

Jewer, J. \& Evermann, J. (2014). Experiential learning with an open-source enterprise system. In 20th Americas Conference on Information Systems, AMCIS 2014.

Kapeso, M. (2014). An introductory mobile ERP training application for SYSPRO users. Undergraduate treatise.

Kerimoglu, O., Basoglu, N., \& Daim, T. (2008). Organizational adoption of information technologies: Case of enterprise resource planning systems. The Journal of High Technology Management Research, 19(1), 21-35. https://doi.org/10.1016/j.hitech.2008.06.002

Khoury, S., Rich, L., \& Jenab, K. (2015). Obstacles to the integration of SAP training in academic programs. Strategic Management Quarterly, 3(1), 95-115. https://doi.org/10.15640/smq. v3n1a4

Kirkham, K. \& Seymour, L. (2005). The value of teaching using a live ERP system with resource constraints. In World Conference on Computers in Education (WCCE), Cape Town.

Kolb, D. A., MacIntyre, J. M., \& Rubin, I. M. (1971). Organizational psychology: An experiential approach. Prentice-Hall.

Korucu, A. T. \& Alkan, A. (2011). Differences between m-learning (mobile learning) and e-learning, basic terminology and usage of m-learning in education. Procedia-Social and Behavioral Sciences, 15, 1925-1930. https://doi.org/10.1016/j.sbspro.2011.04.029

Krotov, V. (2015). Critical success factors in m-learning: A socio-technical perspective. CAIS, 36, 6. 
Léger, P.-M. \& Michon, J.-F. (2011). ERPsim academic version 2011-12. Last checked: 03 Oct 2017. Retrieved from https://www.rjerz.com/sau/misc/SAP/ERPsim_Slides.pdf

Little, B. (2012). Effective and efficient mobile learning: Issues and tips for developers. Industrial and Commercial Training, 44(7), 402-407. https://doi.org/10.1108/00197851211267983

Mahanga, K. M. \& Seymour, L. F. (2015). Enterprise Resource Planning teaching challenges faced by lecturers in Africa. In Proceedings of the 9th IDIA conference, IDIA2015, Nungwi, Zanzibar (pp. 343-353).

Manji, F., Jal, E., Badisang, B., \& Opoku-Mensah, A. (2015). The trajectory of change: Next steps for education. In eLearning africa report (pp. 47-49). Berlin: ICWE.

Merriam-Webster. (n.d.). Definition of simulation. Retrieved from https://www.merriam-webster. com/dictionary/simulation

Minović, M., Štavljanin, V., Milovanović, M., \& Starčević, D. (2008). Usability issues of e-learning systems: Case-study for Moodle learning management system. In On the move to meaningful internet systems: OTM 2008 Workshops (pp. 561-570). Springer.

Momoh, A., Roy, R., \& Shehab, E. (2010). Challenges in enterprise resource planning implementation: State-of-the-art. Business Process Management Journal, 16(4), 537-565. https://doi.org/10. $1108 / 14637151011065919$

Motiwalla, L. F. (2007). Mobile learning: A framework and evaluation. Computers \& education, 49(3), 581-596. https://doi.org/10.1016/j.compedu.2005.10.011

Mutiga, M. \& Flood, Z. (2016). Africa calling: Mobile phone revolution to transform democracies. Retrieved from https://www.theguardian.com/world/2016/aug/08/africa-callingmobile-phone-broadband-revolution-transform-democracies

Nedungadi, P. \& Raman, R. (2012). A new approach to personalization: Integrating e-learning and m-learning. Educational Technology Research and Development, 60(4), 659-678. https: //doi.org/10.1007/s11423-012-9250-9

Ngai, E. W., Poon, J., \& Chan, Y. H. (2007). Empirical examination of the adoption of WebCT using TAM. Computers \& education, 48(2), 250-267. https://doi.org/10.1016/j.compedu.2004.11.007

Nordin, N., Embi, M. A., \& Yunus, M. M. (2010). Mobile learning framework for lifelong learning. Procedia-Social and Behavioral Sciences, 7, 130-138. https://doi.org/10.1016/j.sbspro. 2010.10.019

Oberer, B. \& Erkollar, A. (2013). Mobile learning in higher education: A marketing course design project in Austria. Procedia-Social and Behavioral Sciences, 93, 2125-2129. https://doi.org/ 10.1016/j.sbspro.2013.10.177

Otieno, J. O. (2010). Enterprise Resource Planning systems implementation and upgrade (a Kenyan study) (Doctoral dissertation, Middlesex University).

Oyedemi, T. D. (2012). Digital inequalities and implications for social inequalities: A study of Internet penetration amongst university students in South Africa. Telematics and Informatics, 29(3), 302-313. https://doi.org/10.1016/j.tele.2011.12.001

Panorama Consulting Solutions. (2016). ERP report: A Panorama Consulting Solutions research report. Technical report. 
Plass, J. L., Homer, B. D., \& Hayward, E. O. (2009). Design factors for educationally effective animations and simulations. Journal of Computing in Higher Education, 21(1), 31-61. https: //doi.org/10.1007/s12528-009-9011-x

Santos, J. R. A. (1999). Cronbach's alpha: A tool for assessing the reliability of scales. Journal of extension, 37(2), 1-5.

Scholtz, B., Cilliers, C., \& Calitz, A. (2011). Critical competencies for South African ERP consultants. In Proceedings of the International Business Conference (IBC) (pp. 70-93).

Scholtz, B. \& Kapeso, M. (2014). An m-learning framework for ERP systems in higher education. Interactive Technology and Smart Education, 11(4), 287-301. https://doi.org/10.1108/ITSE09-2014-0030

Shah, S. I. H., Bokhari, R. H., Hassan, S., Shah, M. H., \& Shah, M. (2011). Socio-technical factors affecting ERP implementation success in Pakistan: An empirical study. Australian Journal of Basic and Applied Sciences, 5(3), 742-749.

Sharma, S. K. \& Kitchens, F. L. (2004). Web services architecture for m-learning. Electronic Journal of e-Learning, 2(1), 203-216.

Shih, Y. E. (2007). Setting the new standard with mobile computing in online learning. The International Review of Research in Open and Distributed Learning, 8(2). https://doi.org/10.19173/ irrodl.v8i2.361

SYSPRO. (n.d.). ERP Software | Business Software | Cloud ERP | SYSPRO. Last checked: 30 Sep 2017. Retrieved from https://us.syspro.com

Udanor, C. N. \& Nwodoh, T. A. (2010). A review of m-learning models. Indian Journal of Computer Science and Engineering, 1(4), 426-435.

Uzunboylu, H., Cavus, N., \& Ercag, E. (2009). Using mobile learning to increase environmental awareness. Computers \& Education, 52(2), 381-389. https://doi.org/10.1016/j.compedu. 2008.09.008

Wallace, L. G. \& Sheetz, S. D. (2014). The adoption of software measures: A technology acceptance model (TAM) perspective. Information \& Management, 51(2), 249-259. https://doi.org/10. 1016/j.im.2013.12.003

Wamicha, E. W. \& Seymour, L. F. (1999). A higher education model for developing competencies for critical ERP implementation roles: The case of Kenya. In Beyond development. Time for a new ICT4D paradigm? Proceedings of the 9th IDIA conference (pp. 408-416).

Wetherbe, J. C., Turban, E., Leidner, D. E., \& McLean, E. R. (2007). Information technology for management: Transforming organizations in the digital economy. New York: Wiley. ISBN 0-471$78712-4$.

Whale, A. (2015). An e-learning environment for Enterprise Resource Planning systems (Master's thesis, Nelson Mandela Metropolitan University).

Zhang, W. \& Wang, L. (2005). Learning management systems (LMS) for Web-based distance education: An international review, 245-260. 


\section{A APPENDIX A}

\section{General Instructions}

The project focuses on presenting introductory ERP concepts as well as the application of these concepts through the SYSPRO ERP system. Therefore, one of the technology used is related to the SYSPRO system and the module to be reviewed is the SYSPRO procurement process, that is, the Require-Procure-Pay module. Other modules such as financial, human resource and manufacturing and their respective processes are out of the scope of the project.

The application is evaluated for efficiency, effectiveness and usability. Furthermore, this study will also answer the question of whether an ERP system can be effectively taught by means of m-learning as a method of training.

\section{Instructions for Participants}

1. Select the SYSPRO m-learning application icon

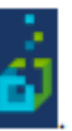

2. View the content under the Theory section. View the content under the following tabs:
a. ERP Systems and History
b. SYSPRO Definition of ERP
c. SYSPRO Processes
d. Require Procure Pay
e. Procure

3. View the video under the Videos tab titled "Require Procure Pay".

4. Complete the Moodle assessment under the Assessment tab.

a. Use your user login (student number) and password

b. Complete "Prac 4 questions"

5. Go back to the application and complete the simulation under the Simulation tab.

a. Select Beginner mode

6. Complete the Post Tasks questionnaire on Moodle for your PC.

Thank you

\section{B APPENDIX B}

\begin{tabular}{|l|c|}
\hline Factor & Cronbach's Alpha \\
\hline Perceived Ease Of Use (PEOU) & 0.82 \\
Perceived Usefulness (PU) & 0.87 \\
\hline
\end{tabular}

Table 6: Cronbach's Coefficient Alphas for the Factors 